that modulate the seasonal and latitudinal distribution (obliquity and precession) and the total amount of incoming solar radiation (eccentricity). Orbital forcing, caused by the gravitational forces of the planets, is the only forcing that can be calculated precisely for several million years back into the past as well as forward into the future. As far as the response is concerned, the situation is much less favourable. Current efforts are focused on the understanding of the suite of reactions triggered by orbital forcing on the various components of the climate system.

On shorter timescales, a variety of climate forcings are at play, including changes in solar activity, occurring on decadal-to-millennial timescales. Changes in the optical properties of the stratosphere due to volcanic activity and dust play a role on interannual-to-decadal scales. In more recent times, human activities have no longer been negligible and affect the boundary conditions of the climate system. At the global scale, human activities are modifying the land surface properties ("land use forcing") and the aerosol and greenhouse content of the atmosphere. These modifications are so intense that the current period is now defined as the "anthropocene". Simultaneously making better use of the archives provided by nature (ice, sediments, tree rings, etc..) leads to new reconstructions of past climate forcings and more realistic representations of forcings in climate models.

Current measurements of solar forcing and attempts to relate it to the observed and reconstructed solar activity is discussed by Judith Lean; indications for a centennial solar effect on the Antarctic atmospheric circulation based on dust records from ice cores are presented by Barbara Delmonte. Volcanic eruptions during the last centuries and their effects on the radiative balance in the atmosphere are the subject of Erich Fischer's contribution; Joël Savarino proposes a new method to identify and possibly quantify the amount of sulphur injected in the stratosphere by volcanic eruptions. Emiliano Castellano and co-authors use high-resolution continuous flow methods on new Antarctic ice cores to reconstruct past changes in volcanic activity, and discuss the possible interaction between this activity and ice sheet extent. Similarly, continuous methods enable new reconstructions of atmospheric dust deposition in Greenland over the last glacial cycle, owing to the NorthGRIP ice core. Fortunat Joos reviews the concept of radiative forcing and climate sensitivity, and the orders of magnitude of current perturbation of the atmosphere radiative balance due to anthropogenic greenhouse gases. Ulrike Lohmann describes the complex role of natural and anthropogenic aerosols on the radiative balance. Even before industrialisation, human activities could have affected the climate system through land use. This issue is addressed by Sandy Harrison.

Today, there are still many open questions regarding climate forcing and response but we can be optimistic that within the next decade we will have better data, improved models and even clearer answers from nature itself.

\title{
Paleoreconstruction of volcanic history inferred from glacio-chemical ice core analyses
}

\author{
E. Castellano 1, ${ }^{2}$, M. Severi ${ }^{1,2}$, R. Traversi ${ }^{1}$, S. Becagli ${ }^{1}$ and R. Udisti ${ }^{1}$ \\ 'Department of Chemistry, University of Florence, Sesto Fiorentino, Italy \\ ${ }^{2}$ MNA, c/o Earth Science Department, University of Siena, Siena, Italy; emiliano.castellano@unifi.it
}

The study of the link between volcanism and climate and the understanding of the actual direction of their causeeffect relationship has been a matter of debate for several years, revealing many aspects not yet well understood. The general scientific approach deals with two main topics:

1. The impact of volcanic emissions (mainly SO, dust, ash) on climate through changes in the Earth's radiative balance, via absorption and scattering of the incoming solar radiation;

2. The possible effect of climate-induced environmental variations (rapid melting or growing of ice sheets with consequent unbalance of the hydrologic cycle-including sea level changes-and of the isostatic pressure on the Earth's crust) on volcanic activity, reflected in changes in frequency and intensity of volcanic events. In reality, the climate-volcanism relationship is more complex and there are several different mechanisms involved, including possible positive feedback mechanisms.

Throwing light on this topic requires the reconstruction of as long and as synchronised paleo-volcanic and paleoclimatic records as possible. In this regard, deep ice cores from the inner regions of Antarctica and Greenland provide a unique archive because they record both past volcanic events (identified by conductivity or sulfate spikes), and indices of past environmental and climatic conditions (e.g. stable isotopes, greenhouse gases, dust).
EPICA Dome C (EDC) ice-core drilling, in the framework of the EPICA (European Project for Ice Coring in Antarctica) project, recently reached bedrock $\left(75^{\circ} 06^{\prime} \mathrm{S}, 123^{\circ} 24 \mathrm{E}, 3233 \mathrm{~m}\right.$ a.s.l., East Antarctic Plateau), allowing the reconstruction of about $900 \mathrm{ky}$ of past climatic history. Chemical and isotopic measurements were carried out at very high temporal resolution, so that single volcanic events (spanning a few years) and fast climatic changes can be reconstructed in large detail over the whole core (EPICA community members, 2004).

The best way to reconstruct paleo-volcanic records from ice cores is to perform high-resolution sulfate measurements. Volcanic eruptions inject huge amounts of $\mathrm{SO}_{2}$ into the atmosphere and, in the case of large explosive eruptions, into the stratosphere, where they can be globally dispersed. Once in the atmosphere, $\mathrm{SO}_{2}$ is oxidised to $\mathrm{H}_{2} \mathrm{SO}_{4}$ within a few weeks, altering the atmospheric composition for months to a few years, and resulting in the contrasting effects of stratospheric heating and tropospheric cooling. $\mathrm{H}_{2} \mathrm{SO}_{4}$ is deposited over polar ice sheets and buried by snow, which accumulates and gradually compresses into solid ice, thereby recording volcanic $\mathrm{H}_{2} \mathrm{SO}_{4}$ signatures.

In the past years, volcanic stratigraphies have often been inferred from continuous acidity records from Electric Conductivity Measurements (ECM) or DiElectric Profiling (DEP) (Udisti et al., 2000). However, the original acidic 
load can be partially neutralised in the atmosphere or after deposition by buffering effects (e.g. by dust). Conversely, sulfate records are insensitive to snow acidity changes and volcanic spikes are irreversibly preserved in the snow, except for very slow processes of diffusion that are only significantly active at great depths.

For these reasons, the paleo-volcanic record of the EDC ice core was reconstructed from sulfate measurements performed in the field by Fast Ion Chromatography (FIC), a method for high-resolution analysis of sulfate, obtained by coupling an ion-chromatographic method with a flowinjection analysis apparatus (Udisti et al., 2000).

EDC-FIC temporal resolution is nearly annual during the whole Holocene, varies from 1 to 5 years during the last $400 \mathrm{ky}$ and then increases up to 25 years at the bottom of the core. Such resolution is high enough to detect most past volcanic events (at least for the last $400 \mathrm{ky}$ ), except for events occurring within a very short time, with only a minor impact on the determination of past volcanic frequencies. The Holocene EDC ice core sulfate profile (Castellano et al., 2005) is presented in Figure 1a, while Figure 1b shows the depositional fluxes of sulfate spikes resulting from volcanic eruptive activity. Sulfate volcanic signals are superimposed on a background of mainly biogenic, marine and crustal origin (see Fig. 1a). The method used for the discrimination between volcanic spikes and background contributions was recently presented (Castellano et al., 2004).

For older periods ( $>400 \mathrm{ky} \mathrm{BP})$, volcanic reconstruction is progressively affected by sulfate diffusion processes, resulting in broader signatures, and by thinning ice-layers, leading to a progressive decrease of volcanic fluxes and of the number of events detected. The possibility to use the volcanic signatures recorded in the whole EDC ice core in the future will depend on the ability to set up

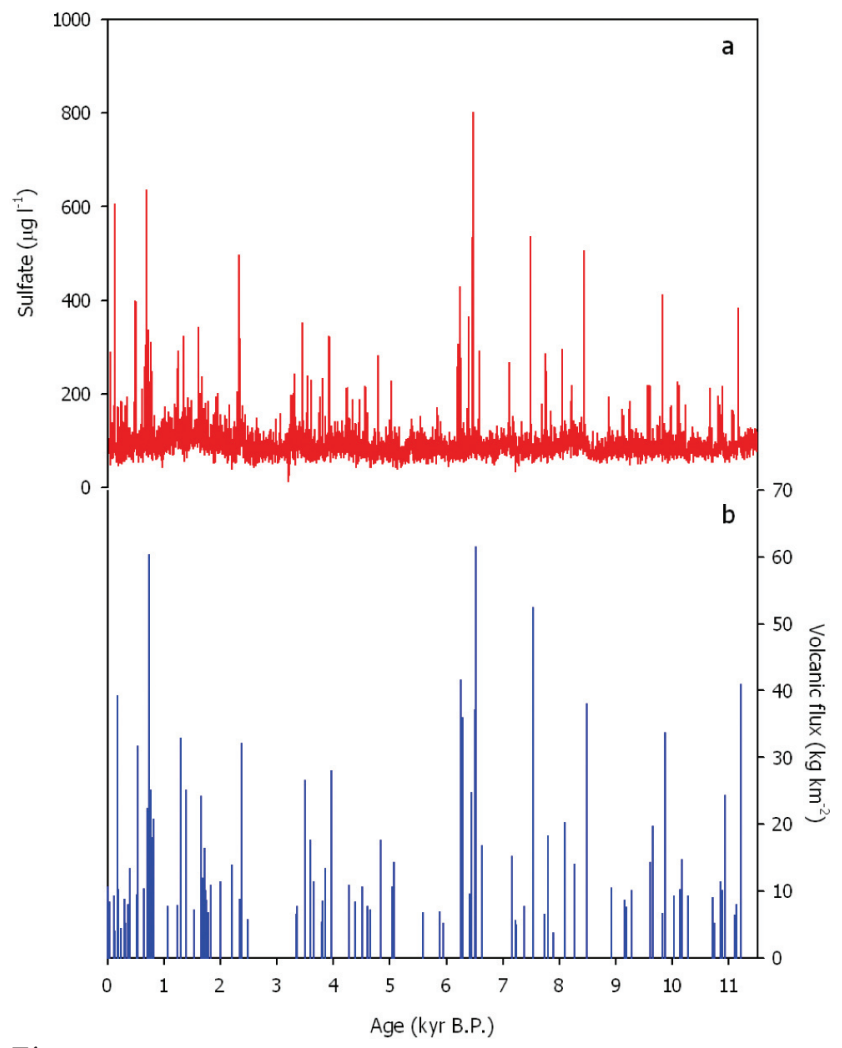

Figure 1

EDC ice core sulfate concentrations (a) and volcanic fluxes (b) spanning the whole Holocene (Castellano et al., 2005). models of volcanic peak deconvolution. In any case, 4-5 reliable glacial/interglacial cycles of volcanic history are already available for correlation with other paleo-climatic records.

Focusing on the younger part of the EDC volcanic record, the comparison between the Holocene volcanic profile with other reconstructions from several Antarctic ice cores indicates that differences in depositional fluxes among different Antarctic locations can be the effect of changes in regional atmospheric circulation, as well as of different mechanisms of atmosphere/snow exchange (Castellano et al., 2005).

In addition, volcanic stratigraphies are useful tools for icecore dating. The high-resolution synchronisation between Vostok and Dome $\mathrm{C}$ volcanic records formed the basis for the construction of a common age scale for the last $45 \mathrm{ky}$, and enabled the detection of changes in the ratio of snow accumulation rates at the two sites (Udisti et al., 2004).

Lately, attention has been focused on studying the climatevolcanism relationship over a longer period of time. Figure 2 shows the comparison between the volcanic frequencies and $\delta \mathrm{D}$, used as a proxy of past atmospheric temperature for a period spanning the last glacial/interglacial cycle (0-150 ky BP).

The volcanic frequency and $\delta \mathrm{D}$ profiles indicate a general inverse correlation between number of volcanic events per millennium and paleo-temperature. A higher occurrence of volcanic signatures is detected around the LGM, MIS 4 and after the Eemian, evidencing the possible enhancement of volcanic activity during cold periods or during phases of rapid climatic transition. This is an interesting aspect of the volcanism-climate relationship that is not yet fully understood and still poorly explored.

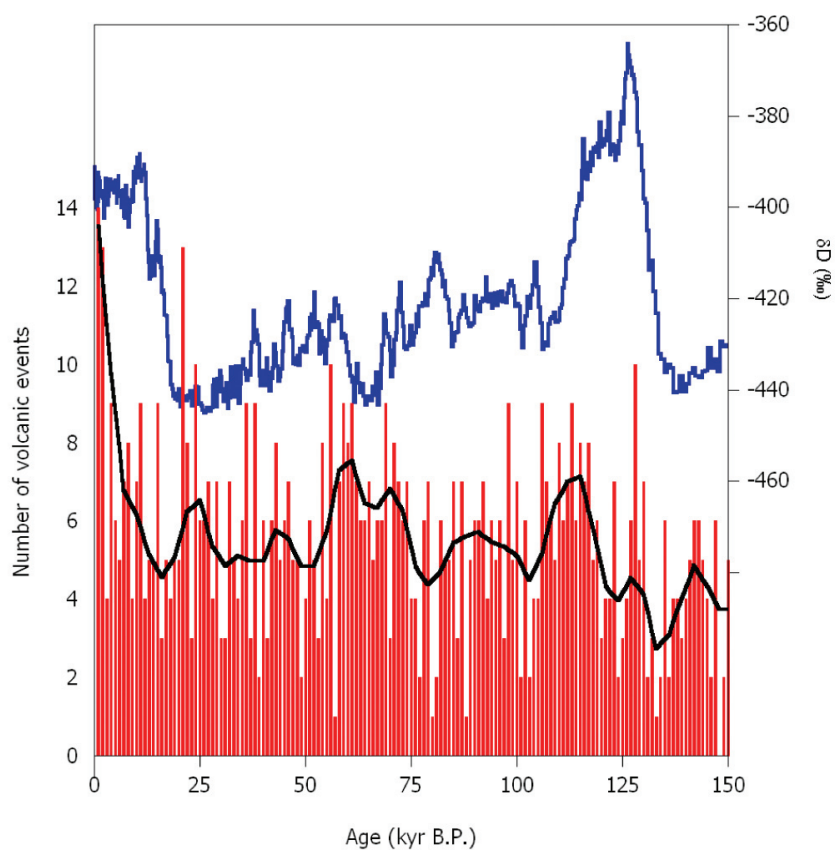

Figure 2

Correlation between number of volcanic events per millennium (red bars, the black solid line represents their smoothed profile) and deuterium (blue line) along the EDC ice core (unpublished data). 
As a preliminary result, such experimental evidence seems to support a close relationship between volcanism and climate, with a sensitivity of volcanic activity to fast temperature changes. This could point to a relevant role of changes in cryosphere and hydrosphere systems (growing or melting of polar ice sheets with consequent change of sea level) in controlling volcanic activity. On the other hand, the fact that the highest number of events are recorded during the two last millennia, something common to several Antarctic ice cores (Castellano et al., 2005), when climatic conditions have been relatively stable, raises new hints and questions for future discussions.

\section{References}

Castellano, E., Becagli, S., Jouzel, J., Migliori, A., Severi, M., Steffensen, J.P., Traversi, R. and Udisti, R., 2004. Volcanic eruption frequency in the last $45 \mathrm{kyr}$ as recorded in EPICA-Dome C ice core (East Antarctica) and its relationship to climate changes. Glob. Planet. Change, 42, 195-205.
Castellano, E., Becagli, S., Hansson, M., Hutterli, M., Petit, J.R., Rampino, M.R., Severi, M., Steffensen, J.P., Traversi, R. and Udisti, R., 2005. Holocene volcanic history as recorded in the sulphate stratigraphy of the European Project for Ice Coring in Antarctica Dome C (EDC96) ice core. J. Geophys. Res., 110, D06114, doi: $10.1029 / 2004 J B 005259$.

EPICA community members, 2004. Eight glacial cycles from an Antarctic ice core. Nature, 429, 623-628.

Udisti, R., Becagli, S., Castellano, E., Mulvaney, R., Schwander, J., Torcini, S. and Wolff, E.W., 2000. Holocene electrical and chemical measurements from the EPICA - Dome C ice core. Ann. Glaciol., 30, 20-26.

Udisti, R., Becagli, S., Castellano, E., Delmonte, B., Jouzel, J., Petit, J.R., Schwander, J., Stenni, B. and Wolff, E.W., 2004. Holocene electrical and chemical measurements from the EPICA - Dome C ice core. J. Geophys. Res., 30, 20-26.

\section{Secular variability and 200-year diploar oscillations in an atmospheric circulation over East Antarctica during the Holocene}

\section{B. Delmonte' ${ }^{1}{ }^{2}$, J.R. Petit' ${ }^{2}$, V. Maggi ${ }^{2}$}

'Laboratoire de Glaciologie et de Géophysique de l'Environnement, Saint Martin d'Hères, France. bdelmonte@nest.it

2Department of Environmental Sciences University Milano-Bicocca, Milano, Italy.

Deep ice cores from the East Antarctic Plateau are unique archives of climate history spanning the Late Quaternary (e.g. EPICA Community Members, 2004; Petit et al., 1999). Insoluble, long-range windblown mineral dust from the Southern Hemisphere continents to the East Antarctic Plateau and archived in the ice layers can be used as a tracer for documenting environmental and atmospheric circulation changes in the Southern Hemisphere at different time scales.

Dust mainly consists of the terrigenous minerals clay, quartz and feldspars. The total concentration in polar ice depends on numerous factors, such as source strength, hydrological cycle, residence time of aerosols, atmospheric transport and snow accumulation rate on the ice sheet. Interestingly, ice core investigations from East Antarctica showed that the grain-size of aeolian minerals is a very useful indicator for atmospheric transport, displaying modes of variability independent from the total dust input (Delmonte et al., 2004). Looking at ice core dust data from these two complementary points of view opens up new perspectives towards improved documentation and better understanding of the dynamics induced by climate forcing at high southern latitudes over the late Quaternary.

A recent dust investigation of two ice cores from East Antarctica (Fig. 1), one from EPICA Dome C (EDC, $75^{\circ} 06^{\prime} \mathrm{S}$ $123^{\circ} 21^{\prime} \mathrm{E}$ ), the other from Vostok (Vostok-BH7, $78^{\circ} 28^{\prime} \mathrm{S}$ $\left.106^{\circ} 48^{\prime} \mathrm{E}\right)$ allowed the depiction of secular and multisecular modes of dust size and atmospheric circulation variability during most of the Holocene (Delmonte et al., 2005). The dust concentration and size profiles along with the water stable isotope content, reported in Fig 1, display clear differences. The total dust input in Antarctic ice is tightly related to environmental conditions at the source regions and a good example is the $~ 800-1,000-$ year-long dust minimum occurring before the Holocene onset (between 12 and 11 kyr BP), likely related to humid conditions in South America, the dominant dust source region for the Antarctic Plateau. Such an event was also found in two other East Antarctic ice cores (Delmonte et al., 2004) and may represent a robust stratigraphic marker. After this event, both EDC and Vostok records display a short-term variability superposed on a main Holocene decreasing trend.

The patterns of dust size changes from both cores (Fig. 1c and $1 \mathrm{~d}$ ) are clearly different with respect to concentration profiles and characterised by a high-frequency (secular to sub millennial) mode of variability. Also, there are evident discrepancies between Vostok and EDC dust size records and the short-term (secular-scale) variations are differently structured in apparent multi-secular and millennial-scale cycles in the two records.

Spectral analyses of the two dust size series for the period of overlap (9.8 to $3.5 \mathrm{kyr} \mathrm{BP}$ ) pointed out significant secularscale periodical modes of variability and an interesting common periodicity around $\sim 200$ years.

A series of volcanic markers randomly distributed over the common part of the records allowed the establishment of a tight stratigraphic and chronological link ( \pm 30 years) between the two records. Interestingly, dust size changes are often asynchronous and out of phase. With respect to the 200-year component, in particular, dust size changes appear out of phase (over 25 cycles from a total of 29) for about 5.5 kyr duration between 9.8 to $4.2 \mathrm{kyr}$ BP.

\section{Regional variability of dust transport and atmospheric circulation patterns over East Antarctica}

The slight dust size fractionation observed in polar ice should depend mostly on transport time and it is likely insensitive to air temperature or water saturation pressure. Therefore, grain-size changes could be associated with the 